\title{
Probabilistic Evaluation of Fatigue Crack Growth Rate for Longitudinal Tungsten Inert Gas Welded Al 6013-T4 Under Various Post- Weld Heat Treatment Conditions
}

\author{
I Made Wicaksana Ekaputra1, ${ }^{*}$, Gunawan Dwi Haryadi², Stefan M ardikus', and \\ Rando Tungga Dewa ${ }^{3}$ \\ ${ }^{1}$ Sanata D harma U niversity, Paingan, M aguwoharjo, D epok, Sleman-Y ogyakarta 55282, Indonesia \\ ${ }^{2}$ Diponegoro U niversity, JI. Prof. Sudharto, SH., Tembalang-Semarang 50275, Indonesia \\ 3 Pukyong National University, 365, Shinsuro, Nam-gu, Busan 608-739, K orea
}

\begin{abstract}
In this study, a M onte Carlo method (M CM ) was applied on the fatigue crack growth rate (FCGR) curves to evaluate a probabilistic assessment for the welded longitudinal AI 6013-T4 aluminum alloy under various post-weld heat treatment (PWHT) conditions. The welded CT specimens were manufactured by a tungsten inert gas (TIG) welding, and the fatigue crack growth (FCG) tests were conducted by following ASTM E647. B efore conducting the FCG test, the PWHT conditions were applied to the welded CT specimens under three different aging times of $6 \mathrm{~h}, 18 \mathrm{~h}$, and $24 \mathrm{~h}$ at $175{ }^{\circ} \mathrm{C}$. The FCGR curves were generated from the FCG data and plotted on the $d a / d N$ versus $\Delta k$ curves. The constants $C$ and $m$ were determined by drawing the fitting line on the FCGR curves. A sizeable random number was generated from the obtained constants by MCM. By plotting these constants, the probabilistic assessment of FCGR was determined on the $d a l d N$ versus $\Delta k$ curves. The results showed that the confidence interval was appeared on the FCGR curves and limited by the upper and lower probabilistic lines. It was found that the lower and upper probabilistic lines were formed at $1 \%$ and $90 \%$, respectively.
\end{abstract}

Key words: Lognormal distribution method, Monte Carlo method, Paris's equation.

\section{Introduction}

For particular aluminum alloy series, the $6 \mathrm{xxx}$ series is mostly used for the components in the aircraft due to their superior characteristics such as high mechanical and fatigue strength, good formability and weldability, and good corrosion resistance [1-3]. The 6xxx series can be found mainly on the structural components in the aircraft, such as for the fuselage skins. The welding method becomes the most straightforward and economist ways for the manufacturing process. It has been reported that the gas metal arc welding (GMAW) and tungsten inert gas (TIG) was the conventional welding methods used for joining

\footnotetext{
${ }^{*}$ Corresponding author: made@ usd.ac.id
} 
process in aluminum alloys [1]. The GMAW can be operated in the high welding speed with good penetration depth.

Furthermore, the welding process can be performed continuously regardless of the electrode usage for the limited length [4-5]. However, the problems such as melt through, distortion, etc., appears due to high heat input, especially for the aluminum with the particular thicknesses. The TIG welding tends to be preferred over the GMAW since it can perform the joining process well for the wide variety of metals and a wide range of workpiece thicknesses and shapes.

In general, the welding process will affect the mechanical properties of the welded area, even though the chosen welding method has good weldability. The weld metal (WM) and heat-affected zone (HAZ) areas tend to become harder and more fragile than the base metal (BM) area. The risk of hot cracking appearance may increase, and some properties such as toughness, ductility, fatigue strength, etc. may fall on a degradation $[4,6,7]$. It has been reported that those mechanical properties of the welded material can be improved by applying a post-weld heat treatment (PWHT) for a particular period and temperature $[8,9]$.

In the aircraft application, a fatigue crack growth (FCG) problem becomes one of the main concerns since most of the components experience a fluctuation load. An accurate assessment of a fatigue crack growth rate (FCGR) must be evaluated carefully for the design and safety requirements. Some difficulties were found when the assessment was only determined by a few data of the FCG test. The FCGR could not be predicted precisely due to the data deviation. Therefore, an approach method is needed to construct an accurate FCGR prediction from limited data of the FCG test.

In this study, the probabilistic assessment of FCGR for the welded longitudinal Al 6013-T4 aluminum alloy is investigated by a Monte Carlo method (MCM). The FCGR data was obtained from the FCG test by following the ASTM E647 under three different PWHT conditions. The probabilistic assessment is plotted on the $d a / d N$ versus $\Delta k$ curves, and the results are discussed.

\section{Experimental procedures}

The chemical composition of the base metal Al 6013 aluminum alloy is listed in Table 1. The welded metal was manufactured by TIG welding process in a longitudinal direction, as shown in Figure 1. The welded metal was in the plate form with $2.5 \mathrm{~mm}$ of thickness. The electrode wire of Al 5356 was used as filler with the $3.2 \mathrm{~mm}$ of diameter.

Table 1. The chemical composition of the Al 6013 aluminum alloy (wt.\%).

\begin{tabular}{|l|c|c|c|c|c|c|c|c|c|}
\hline Materials & $\mathbf{S i}$ & $\mathbf{F e}$ & $\mathbf{C u}$ & $\mathbf{M n}$ & $\mathbf{M g}$ & $\mathbf{C r}$ & $\mathbf{Z n}$ & $\mathbf{T i}$ & $\mathbf{A l}$ \\
\hline Al 6013 T4 & 0.66 & 0.09 & 0.80 & 0.39 & 1.04 & 0.07 & 0.06 & 0.02 & B al. \\
\hline
\end{tabular}




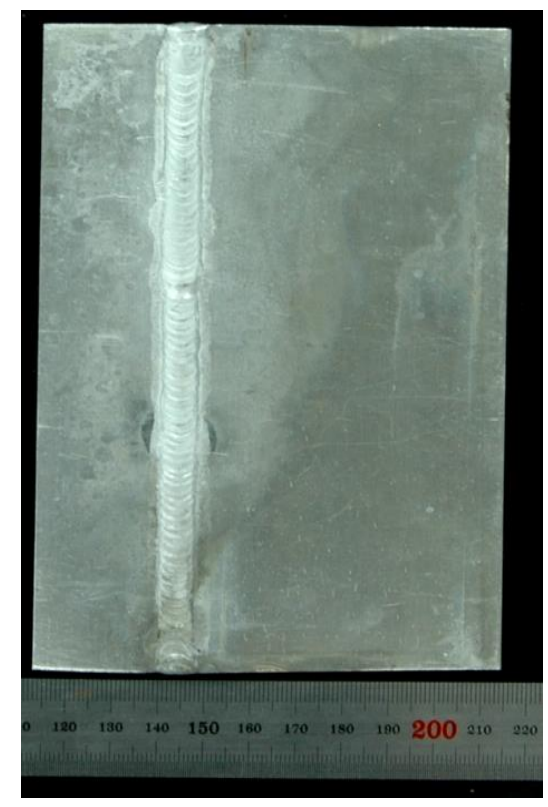

Fig. 1. The welded plate by TIG on the longitudinal direction.

The contamination during the welding process was prevented by applying a shielding gas of ultra-high purity (UHP) of $99.95 \%$ Argon (Ar). The TIG process was conducted by following the welding parameters as follows:
i. Polarity
: DCEP
ii. Welding speed
$: 2.5 \mathrm{~mm} \mathrm{~s}^{-1}$
iii. Voltage
$: 15 \mathrm{~V}$
iv. Current
$: 70 \mathrm{~A}$
v. Gas flow rate
: $15 \mathrm{~L} \mathrm{~min}^{-1}$
vi. Aging temperature
$: 175^{\circ} \mathrm{C}$

The compact tension (CT) specimen was used for the FCG test. The CT specimens were manufactured from the welded plate with the dimensions of $300 \mathrm{~mm} \times 100 \mathrm{~mm} \times 2.5$ $\mathrm{mm}$ and $12 \mathrm{~mm}$ of the initial crack length, as shown in Figure 2. The initial crack was made by using an electric discharge machine (EDM). The FCG tests were conducted by following the ASTM E647 standard, and the CT specimens were initially heat-treated by solution heat-treated ( $\mathrm{t} 4)$ method. The CT specimens were initially heated at $425{ }^{\circ} \mathrm{C}$ for two $\mathrm{h}$, and then the cold work was applied to the specimen to produce $2 \%$ strain hardening. Further, three different aging times of $6 \mathrm{~h}, 18 \mathrm{~h}$, and $24 \mathrm{~h}$ were applied at $175^{\circ} \mathrm{C}$.

The MCM was applied to determine the probabilistic assessment on the FCGR curve. This method involves a large random number to generate a prediction calculation from a particular set of constants in the FCGR Equation. The set of constants consist of $C$ and $m$ that is known as material constants in Paris's Equation. The Equation is formulated as follows:

$$
\frac{d a}{d N}=C(\Delta K)^{m}
$$

where $d a / d N$ is the fatigue crack growth rate ( $\mathrm{mm} / \mathrm{cycles})$ and $\Delta k$ is the stress intensity factor ( $\mathrm{M} \mathrm{Pa} \mathrm{m} \mathrm{m}^{1 / 2}$ ). 

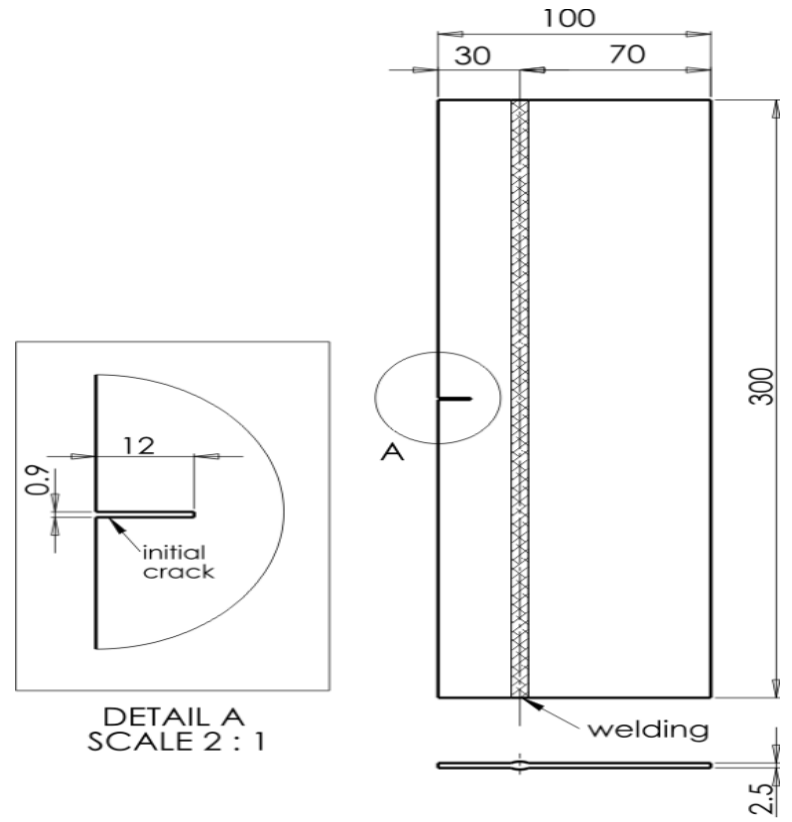

Fig. 2. The CT specimen.

\section{Results and discussion}

Figure 3 shows the FCGR curves of the welded Al 6013-T4 under three different aging times. A regression line is fitted on the combined curves by a linear square fitting method (LSFM). Paris's Equation is applied on the fitted line, and the constants $C$ and $m$ are obtained. The obtained constants $C$ and $m$ are 7.71E-15 and 8.03, respectively. The LSFM is also applied to each aging time curve, and the constant values of $C$ and $m$ for each curve are summarized in Table 2 . It is shown that $m$ exponent slightly reduces at $18 \mathrm{~h}$. It has been reported that $m$ exponent corresponded to the FCGR resistance [1]. The FCGR resistance will decrease with a decrease in $m$ exponent value.

The combined curve constants show a significant difference with the obtained constants in Table 2. Since the LSFM is easily influenced by the number of data scattering on the FCG data points, the LSFM on the combined curve tends to result in a deviation. As a result, the constants $C$ and $m$ are higher than the values in Table 2 . In this study, the constants $C$ and $m$ are based on the values in Table 2 . The average value is determined by evaluating from the probability graph, as shown in Figure 4 . The $50 \%$ probability and standard deviation of each constant are obtained by applying the lognormal distribution method (LDM). The values of each constant are summarized in Table 3.

Figure 5 shows a large random number of constants $C$ and $m$ generated by M CM. The random number is produced about 30000 data points. This random number is generated by applying random variables on a standard normal distribution. This method was first time proposed by Box and Muller and had been previously applied to determine a probabilistic assessment of creep crack growth rate (CCGR) for Gr.91 steel [10]. The M CM has been reported as a method that was successful in predicting the CCGR from limited data of creep crack growth (CCG). Figure 6 shows the confidence interval limited by the upper and lower probabilistic lines on FCGR curve. The confidence interval corresponded to the rational/non-rational prediction for the fastest and lowest of FCGR. Figure 6 it is shown that the lower and upper probabilistic lines for welded Al 6013-T4 were formed at $1 \%$ 
and $90 \% .1 \%$ and $90 \%$ are determined since these values can cover all of the experimental data. The $1 \%$ probability line is determined as the non-rational prediction, while the $90 \%$ probability line is determined as the rational prediction.

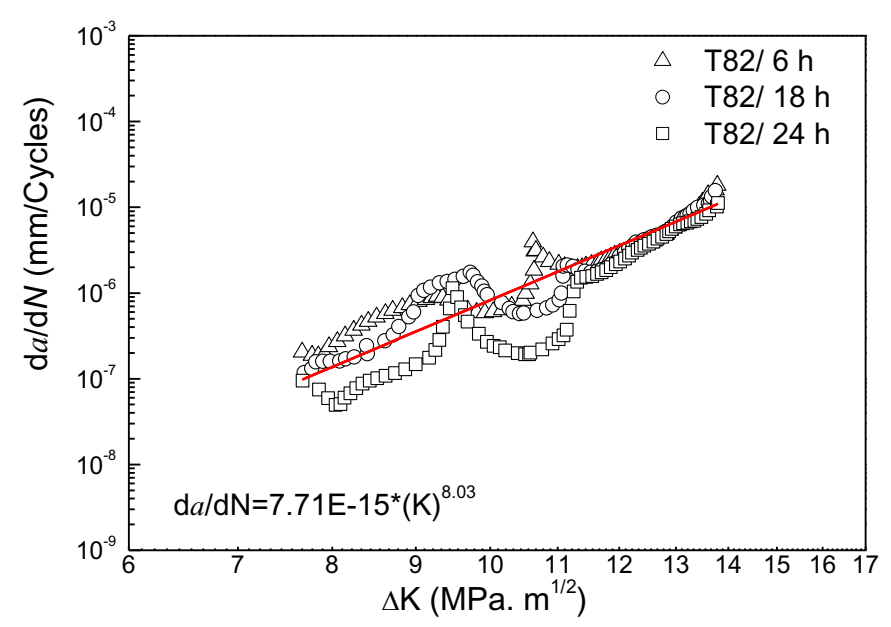

Fig. 3. The FCGR of welded AI 6013-T4 al uminum alloy under three different aging times.

Table 2. The constants $C$ and $m$ under three different aging times.

\begin{tabular}{|c|c|c|}
\hline Aging time (h) & $\boldsymbol{C}$ & $\boldsymbol{m}$ \\
\hline 24 & $1.93 \mathrm{E}-14$ & 7.60 \\
\hline 18 & $2.92 \mathrm{E}-14$ & 7.23 \\
\hline 6 & $5.02-14$ & 7.34 \\
\hline
\end{tabular}

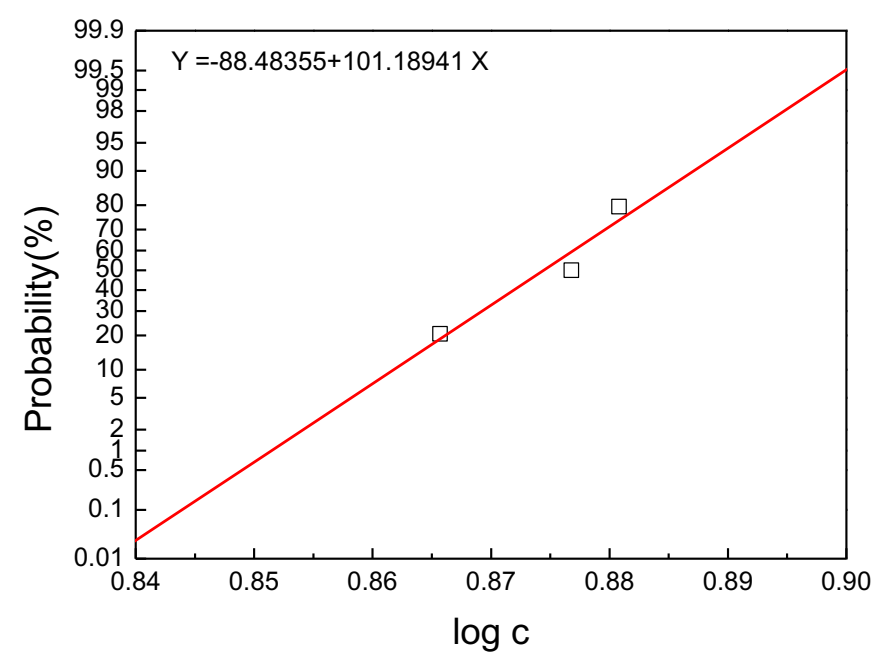

(a) 


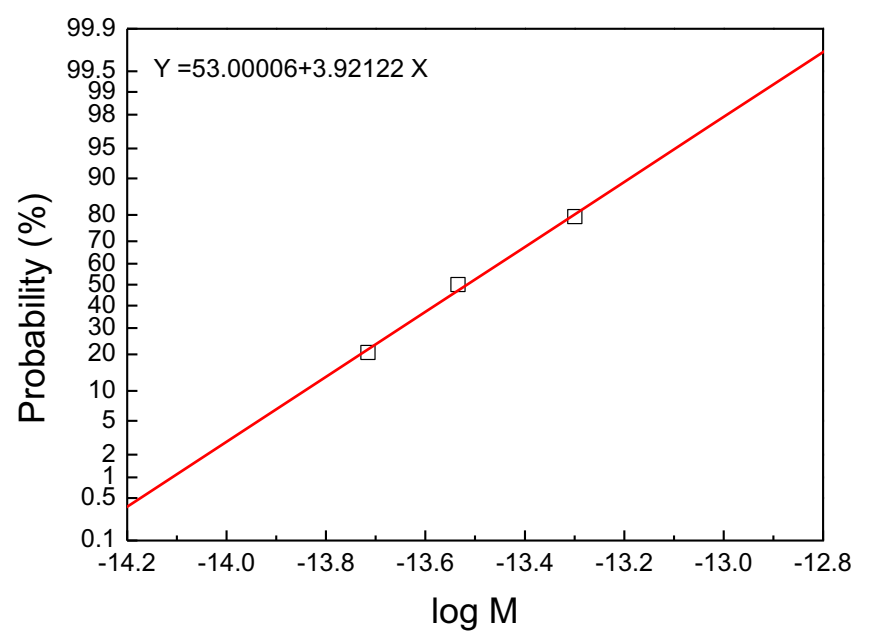

(b)

Fig. 4. The constants $C(\mathrm{a})$ and $m$ (b) in probability graph.

Table 3. The $50 \%$ probability of constants $C$ and $m$ obtained by LDM .

\begin{tabular}{|c|c|c|}
\hline & $\log \boldsymbol{C}$ & $\log \boldsymbol{m}$ \\
\hline 50 \% probability & 0.8744 & -13.5162 \\
\hline Standard deviation & 0.0078 & 0.2087 \\
\hline
\end{tabular}

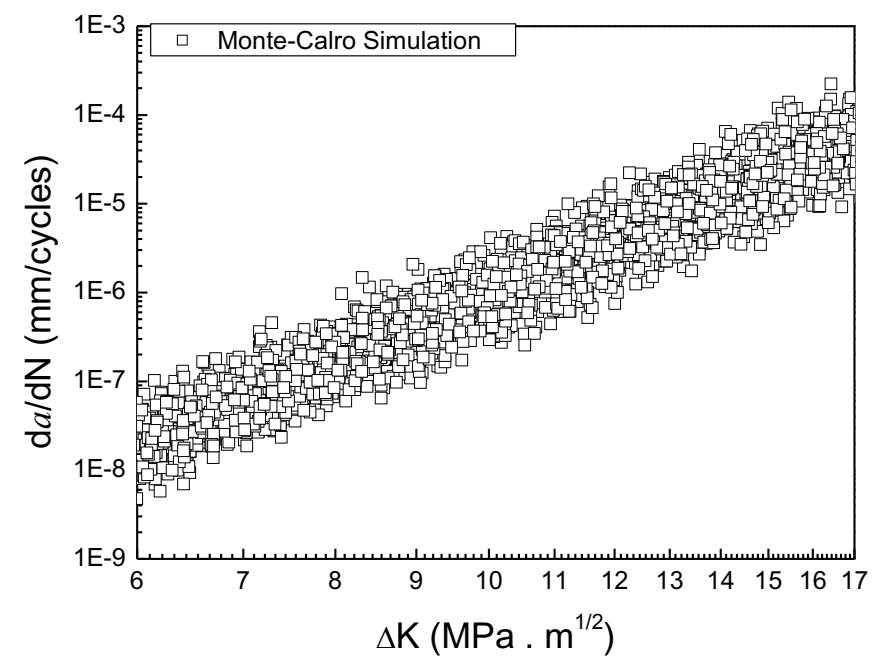

Fig. 5. The FCGR data generated by MCM . 


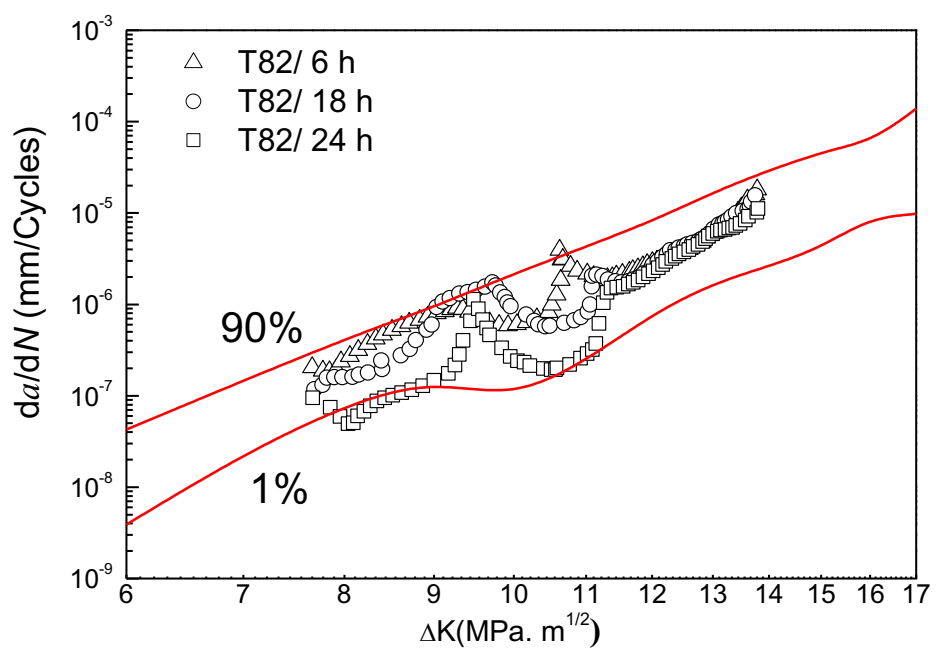

Fig. 6. The confidence interval with the lower and upper probabilistic lines on FCGR curve.

\section{Conclusions}

In this paper, the FCGR of welded Al 6013-T4 has been probabilistically assessed by the MCM. The MCM was able to predict the confidence interval with the upper and lower probabilistic lines at $90 \%$ and $1 \%$, respectively. By using these probabilities, the FCGR lines could be probabilistically assessed using only a particular limit of FCG data. It was found that MCM was suitable to be applied as a prediction tool for FCGR since it can perform a rational prediction at $90 \%$. This rational prediction was defined as the fastest FCGR. On the other hand, the $1 \%$ probability was the non-rational prediction where the lowest FCGR occurred.

\section{References}

1. G.D. Haryadi, R.T. Dewa, I.M.W. Ekaputra, J. Theor. Appl. Mech., 56,1:179_ 190(2018). http://jtam.pl/Fatigue-crack-growth-and-probability-assessment-fortransverse-TIG-welded-A luminum,101704,0,2.html

2. E.F.A. Zeid, J. M ater. Res. Technol., 8,2:1870-1877(2019). https://www.sciencedirect.com/science/article/pii/S2238785418306823

3. W.J. Liang, P.A. Rometsch, L.F. Cao, N. Birbilis, Corros. Sci., 76:119-128(2013). https://www.sciencedirect.com/science/article/pii/S0010938X 13002783

4. I.M.W. Ekaputra, S. M ungkasi, G.D. Haryadi, R.T. Dewa, S.J . K im. The influence of welding speed conditions of GMAW on mechanical properties of $316 \mathrm{~L}$ austenitic stainless steel. International J oint Conference on A dvanced Engineering Technology and International Symposium on A dvanced M echanical and Power Engineering (Bali, Indonesia, 2017). M atec Web of Conferences 159,02009:1-6(2018). https://www.matec-conferences.org/articles/matecconf/abs/2018/18/matecconf_ijcaetisampe2018_02009/matecconf ijcaet-isampe2018 02009.html

5. A.K. Lakshminarayanan, V. Balasubramanian, K. Elangovan, Int. J. Adv. M anuf. Technol., 40,3-4:286-296(2009). https://link.springer.com/article/10.1007/s00170007-1325-0 
6. J. Hensel, T.N. Pagel, D.T. N goula, H.T. B eier, D. Tchuindjang, U. Zerbst, Eng. Fract. M ech., 198:123-141(2018).

https://www.sciencedirect.com/science/article/pii/S0013794417303326

7. R.T. Dewa, J.H. Park, S.J. Kim, W.G. Kim, E.S. Kim, G.D. Haryadi, et al . A review of low-cycle fatigue of Alloy 617 for use in VHTR components: experimental outlook.

International Joint Conference on A dvanced Engineering Technology and International Symposium on A dvanced M echanical and Power Engineering (Bali, Indonesia, 2017). M atec Web of Conferences 159,02049:1-6(2018). https://www.matecconferences.org/articles/matecconf/abs/2018/18/matecconf_ijcaetisampe2018 02049/matecconf ijcaet-isampe2018_02049.html

8. G. Yan, M .J. Tan, A. Crivoi, F. Li, S. Kumar, C.H.N. Chia, Procedia Eng., 207:633638(2017). https://www.sciencedirect.com/science/article/pii/S1877705817358265

9. M .N. Gussev, N. Sridharan, M. N orfolk, K .A. Terrani, S.S. B abu, M ater. Sci. Eng., A, 684:606-616(2017).

https://www.sciencedirect.com/science/article/abs/pii/S0921509316315866

10. W.G. Kim, J.Y. Park, S.D. Hong, S.J. Kim, Nucl. Eng. Des., 241:3580-3586(2011). https://www.sciencedirect.com/science/article/pii/S0029549311005255 